Esta revista forma parte del acervo de la Biblioteca Jurídica Virtual del Instituto de Investigaciones Jurídicas de la UNAM http://www.juridicas.unam.mx

https://biblio.juridicas.unam.mx

https://revistas.juridicas.unam.mx

DOI: http://dx.doi.org/10.22201/iij.24487899e.2021.32.15307

ARTÍCULOS

Sy 


\title{
DISCURSOS CONSTITUCIONALES Y SISTEMAS DE PROTECCIÓN SOCIAL EN AMÉRICA LATINA Y EL CARIBE*
}

\author{
CONSTITUTIONAL SPEECHES AND SOCIAL PROTECTION \\ SYSTEMS IN LATIN AMERICA AND THE CARIBBEAN \\ DISCOURS CONSTITUTIONNELS ET SYSTÈMES DE \\ PROTECTION SOCIALE EN AMÉRIQUE LATINE \\ ET DANS LES CARAÏBES
}

\section{Guillermo Alfonso MALDONADO SIERRA**}

RESUMEN: El discurso de los derechos ha ocupado un espacio histórico preponderante en el constitucionalismo de América Latina y el Caribe (ALC), impulsado con la llegada del constitucionalismo social a la región a principios del siglo XX, la constitucionalización del derecho a partir de la década de los ochenta, y los nuevos constitucionalismos latinoamericanos del presente siglo.

El derecho a la seguridad social ha sido parte de esta dinámica en la medida que cuenta con una dilatada trayectoria en su reconocimiento constitucional en los países de la región, reflejada en la creación de sistemas de seguridad social y posterior surgimiento de sistemas de protección social, todo lo cual contrasta con la situación persistente de pobreza, desigualdad y baja cobertura de los sistemas contributivos de la seguridad social en la Población Económicamente Activa (PEA) de ALC, y que la sumerge en una gran paradoja: a mayor realización de este derecho, menor es el interés de consagrarlo constitucionalmente, mientras que a menor goce efectivo del mismo, mayor es el reconocimiento constitucional que recibe, aspecto que podría catalogarse como una expresión del populismo político y normativo imperante en varios países de la región.

* Recibido el 5 de mayo de 2020 y aceptado para su publicación el 3 de septiembre de 2020.

** Abogado especialista en derecho constitucional y magíster en protección social de la Universidad Santo Tomás, sede Bogotá, Colombia.

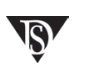


Palabras clave: América Latina y el Caribe, constitucionalización, populismo, protección social, seguridad social.

ABSTRACT: The discourse of rights has occupied a preponderant historical space in the constitutionalism of Latin America and the Caribbean (ALC), driven by the arrival of social constitutionalism in the region in the early twentieth century, the constitutionalization of law from the decade of the eighty, and the new Latin American constitutionalisms of the present century.

The right to social security has been part of this dynamic, to the extent that it has a long history in its constitutional recognition in the countries of the region, reflected in the creation of social security systems and subsequent emergence of social protection systems, all of which contrasts with the persistent situation of poverty, inequality and low coverage of social security contributory systems in the Economically Active Population (PEA) of LAC, and which also immerses it in a great paradox: the greater realization of this right The lower the interest of constitutionally consecrating it, while the less effective enjoyment thereof, the greater the constitutional recognition it receives, an aspect that could be classified as an expression of the political and normative populism prevailing in several countries of the region.

Keywords: Constitutionalization, Latin America and the Caribbean, populism, social protection, social security.

RÉSUMÉ: Le discours des droits a occupé un espace historique prépondérant dans le constitutionnalisme de l'Amérique latine et des Caraibes (ALC), entraîné par l'arrivée du constitutionnalisme social dans la région au début du XXe siècle, la constitutionnalisation du droit à partir de la décennie du quatre-vingt et les nouveaux constitutionnalismes latinoaméricains du siècle actuel.

Le droit à la sécurité sociale fait partie de cette dynamique, dans la mesure où il a une longue histoire dans sa reconnaissance constitutionnelle dans les pays de la région, reflétée dans la création de systèmes de sécurité sociale et l'émergence ultérieure de systèmes de protection sociale, qui contraste avec la persistance de la pauvreté, des inégalités et de la faible couverture des systèmes contributifs de sécurité sociale dans la population économiquement active (APE) de la région ALC, et qui l'immerge également dans un grand paradoxe: la plus grande réalisation de ce droit Plus l'intérêt de la consacrer constitutionnellement est faible, tandis que sa jouissance est moins efficace, plus sa reconnaissance 
constitutionnelle est grande, un aspect qui pourrait être classé comme l'expression du populisme politique et normatif qui prévaut dans plusieurs pays de la région.

Mots-clés: Amérique latine et Caraibes, constitutionnalisation, populisme, protection sociale, sécurité sociale.

SUMARIO: I. Introducción. II. Los origenes de los sistemas de seguridad social en América Latina y el Caribe. III. Los sistemas de protección social en América Latina y el Caribe. IV. La consagración constitucional del derecho a la seguridad social en América Latina y el Caribe. V. Conclusiones. VI. Fuentes de investigación.

\section{INTRODUCCIÓN}

$\square$ n la historia del constitucionalismo moderno occidental, se observa recurrentemente que las Constituciones no solamente se han ocupado de organizar y alternar racionalmente el poder político, como mecanismo democrático para procurar por la convivencia pacífica de las sociedades, sino que en sus cartas políticas también ocupa un espacio preponderante el discurso de los derechos, bien sea para aplacar a las mayorías ávidas de cambios sociales, o para expresar en sus textos aquellos anhelos o utopías que denotan los deseos de progreso de los pueblos, o sus frustraciones ante las promesas fallidas de la democracia.

Sin embargo, desde la propuesta habermasiana del principio discursivo, la acción comunicativa y su acercamiento al Estado democrático de derecho, la producción de las normas jurídicas debe caracterizarse por contar con un juicio reflexivo por medio del cual los individuos y grupos acuerdan su expedición mediante razones válidas para todos los afectados, bajo un marco público lo más amplio posible en el que tengan cabida las diversas concepciones y expresiones racionales.

En ese ámbito, los principios y normas generales se deben aplicar de manera imparcial al contexto en sus planos ético, democrático y jurídico, para posibilitar no sólo a los ciudadanos, sino también al legislador y al juez, decidir si en la justificación y aplicación de los derechos fundamentales se han ofrecido todas las garantías democráticas existentes, de manera que la acción comunicativa resulta relevante para la búsqueda de la integración social en 
aquellas sociedades donde el componente conflictivo es demasiado alto y excluyente. ${ }^{1}$

Específicamente, el arribo del constitucionalismo social y la consagración de los primeros derechos laborales entre finales del siglo XIX y principios del siglo XX, tuvo como premisas esenciales contener el avance del comunismo y compensar los estragos de las guerras mundiales, objetivos que en varios países de la Europa occidental dieron lugar al Estado de bienestar que se erigió como garante de los derechos sociales, y que en varias latitudes del mundo intentó ser replicado, entre ellas América Latina y el Caribe (ALC).

Aunque la seguridad social tradicionalmente ha estado inmersa dentro del paquete de derechos sociales reconocidos por el constitucionalismo social en ALC, en un grupo importante de estos países la estructuración de este derecho estuvo marcada por la irrupción de dictaduras militares, golpes de estado y restricciones democráticas, que al menos en el ámbito normativo paradójicamente propendieron por su expansión y desarrollo, mientras que a partir de la década de los ochenta se presentó un proceso continuo de restablecimiento de las democracias y transformación hacia un constitucionalismo pluralista que activó la justicia constitucional, con una notable incidencia en el auge de la constitucionalización de la seguridad social.

De este modo, en el presente artículo se rastrean los orígenes de los sistemas de seguridad social en ALC, para luego mostrar la evolución de este concepto hacia la protección social y examinar el desempeño actual de estos sistemas en la región y su relación con el Producto Interno Bruto (PIB) de cada país; estas premisas son confrontadas con el proceso de incorporación constitucional del derecho a la seguridad social en ALC, y su consagración hoy día desde el punto de vista cuantitativo, con el fin de establecer la relación existente entre el discurso constitucional de la seguridad social y la concreción efectiva de este derecho.

Cabe destacar que de este estudio se sustraen los países caribeños de la commonwealth británica, debido a que su adscripción histórica a la tradición legal del common law, hace que sus constituciones marquen el énfasis en los derechos civiles y políticos, mientras que los derechos económicos, sociales y culturales (DESC) y las acciones constitucionales para su efectividad no aparentan ser un asunto relevante para los poderes políticos de la zona; ${ }^{2}$ empero,

1 Durango, Gerardo, "El principio discursivo y los derechos fundamentales en la teoría habermasiana”, Revista Opinión Jurídica, Universidad de Medellín, 2006, pp. 13-32.

2 Solamente la Constitución de Belice de 1981 alude discretamente a la seguridad social y a la salud en su preámbulo, mientras que la Constitución de Guyana de 1980 es la única que 
esto no quiere decir que el derecho a la seguridad social no se garantice a los habitantes de esa región, puesto que en estos países también hay una amplia experiencia en la expedición de normas sobre seguridad social ${ }^{3}$ y ejemplos de desempeño sobresalientes.

\section{LOS ORÍGENES DE LOS SISTEMAS DE SEGURIDAD SOCIAL EN AMÉRICA LATINA Y EL CARIBE}

$\longrightarrow$ n términos generales, la seguridad social en su acepción moderna ha pasado por tres grandes etapas: i) los sistemas iniciales de protección, dentro de los que se encuentran el ahorro individual, la mutualidad, el seguro privado, la asistencia pública y la responsabilidad de los riesgos profesionales; ii) la creación de los seguros sociales, atribuida al canciller alemán Otto Bismarck, quien ideó el seguro obligatorio contra accidentes y enfermedades dirigido y controlado por el Estado para proteger a los trabajadores de la industria en forma obligatoria, contra el riesgo de enfermedad y la contingencia de la maternidad, y iii) la seguridad social propiamente dicha, que no solamente se ocupa de proteger a los trabajadores por cuenta ajena, sino que surge con el propósito de amparar a toda la población contra los riesgos y contingencias a que están sujetos, surgida en Estados Unidos en 1936 para hacer frente a la

establece el derecho de los ciudadanos de la tercera edad y los discapacitados a recibir atención en salud y asistencia social gratuita. Acontece lo contrario con los derechos pensionales, puesto que todas las cartas fundamentales del Caribe anglófono dedican amplias secciones para precisar aspectos como la aplicabilidad y favorabilidad de las leyes pensionales antes y después de la independencia política del país respectivo, la obligación de reconocer los beneficios pensionales con cargo a un fondo consolidado, las situaciones en las cuales se puede retener o reducir las pensiones, los derechos pensionales de los trabajadores estatales, entre otros, siendo manifiesta la preocupación de estos países por salvaguardar la sostenibilidad financiera de sus sistemas pensionales.

3 Por ejemplo, en Antigua y Barbuda desde 1956 rige la Ley de Compensación para Trabajadores, y en 1970 el gobierno aprobó la Ley del Fondo Nacional de Previsión cuya implementación nunca se materializó, hasta que el 11 de julio de 1972 se expidió la Ley de Seguridad Social, convirtiéndose en el primer Estado del Caribe Oriental en haber introducido un sistema de seguridad social y el quinto sistema funcional de seguridad social en el Caribe de habla inglesa; esta Ley incluyó disposiciones para el pago de la pensión a los 60 años, pensiones de invalidez y de sobrevivientes, beneficios por enfermedad, maternidad y funeral, así como la definición de créditos para la introducción de prestaciones por accidentes laborales, que se otorgaron en virtud de la Ley de Indemnización por Accidentes del Trabajo. 
crisis económica que asolaba el país, siendo éste un mecanismo que se extendió hacia otras latitudes del mundo a partir de la segunda postguerra. ${ }^{4}$

Estas fases presentaron un claro desarrollo en ALC, en tanto que la creación y acceso inicial a la seguridad social estuvo restringida a grupos de poder como los militares, sindicatos y servidores públicos, para luego trasegar a modelos de corte bismarckiano en los que en el marco de la ciudadanía laboral regulada se garantizaron derechos a los trabajadores regidos por un contrato laboral, presentando posteriormente esfuerzos de universalización a través de la expansión de los beneficios de la protección social a otros grupos poblacionales, a través de la implementación de medidas bastante sui generis en la región como son las transferencias económicas condicionadas.

A finales de la década de los setenta del siglo pasado, todos los países de ALC tenían implementados programas de seguro social, con algunas particularidades que hacen posible clasificarlos en tres grandes grupos conforme a la época en que introdujeron tales programas y el grado de desarrollo que alcanzaron, así:

- El grupo pionero-alto conformado por Uruguay, Argentina, Chile, Cuba, Brasil y Costa Rica, países que establecieron los primeros sistemas de seguros sociales en la región en los años veinte y treinta del siglo XX, con niveles importantes de cobertura y desarrollo.

- El grupo intermedio constituido por Panamá, México, Perú, Colombia, Bolivia, Ecuador y Venezuela, quienes implementaron sus programas en las décadas cuarenta y cincuenta del siglo XX influenciados por el Informe Beveridge y los convenios de la OIT, logrando una cobertura media en sus sistemas.

- El grupo tardío-bajo, del cual hacen parte Paraguay, República Dominicana, Guatemala, El Salvador, Nicaragua, Honduras y Haití, que introdujeron sus programas de seguridad social en los años sesenta y setenta del siglo XX, con menor cobertura y desarrollo de sus sistemas. ${ }^{5}$

4 Nugent, Ricardo, "La seguridad social: su historia y sus fuentes", en Buen Lozano, Néstor de, y Morgado Valenzuela, Emilio (coords.), Instituciones de derecho del trabajo y de la seguridad social, México, AIDTSS-UNAM, 1997, pp. 606-617, disponible en: https:// biblio.juridicas.unam. $m x /$ bjv/detalle-libro/139-instituciones-de-derecho-del-trabajo-y-de-la-seguridad-social.

5 Mesa-Lago, Carmelo, "Las reformas de pensiones en América Latina y su impacto en los principios de la seguridad social", Serie 144 - Financiamiento del desarrollo, 2004, pp. 1-137, disponible en: bttps:// wmw.cepal.org/es/publicaciones/5126-reformas-pensiones-america-latina-su-impactoprincipios-la-seguridad-social. 


\section{LOS SISTEMAS DE PROTECCIÓN SOCIAL EN AMÉRICA}

\section{LATINA Y EL CARIBE}

$\mathrm{E}$ $\mathrm{n}$ los análisis contemporáneos en la materia es recurrente observar la ubicación de la seguridad social dentro de una noción más amplia como es la protección social, concepto que "tiene por objetivos garantizar un ingreso que permita mantener niveles mínimos de calidad de vida para el desarrollo de las personas; posibilitar el acceso a servicios sociales y de promoción, y procurar la universalización del trabajo decente", ${ }^{6}$ de manera que para lograr esos objetivos abarca tres grandes componentes, como son: 1) la protección social no contributiva o asistencia social, que incluye medidas tanto universales como focalizadas; 2) la protección social contributiva o seguridad social, y 3) la regulación de los mercados laborales, que consiste en la expedición de normas y estándares orientados a fomentar y proteger el trabajo decente. ${ }^{7}$

Ahora bien, confrontando los antecedentes históricos del surgimiento de los sistemas de seguridad social en ALC con el desempeño actual de los sistemas de protección social en la región, se observa que la clasificación de estos subgrupos no ha diferido mucho en el tiempo, en tanto que un estudio realizado a partir de la medición del Índice de Protección Social de 2012, el cual se construyó sobre las dimensiones de universalidad, solidaridad y gasto social de 18 países de la región, ${ }^{8}$ se elaboraron tres categorías de países de acuerdo con las puntuaciones finales alcanzadas, de este modo:

- El grupo de Uruguay, Chile, Costa Rica, Argentina y Brasil, países que obtuvieron la calificación más alta debido a que cuentan con sistemas de

6 Cecchini, Simone y Martínez, Rodrigo, "Protección social inclusiva en América Latina. Una mirada integral, un enfoque de derechos", Santiago de Chile, 2011, pp. 18, disponible en: https:/ / repositorio.cepal.org/ bitstream/ handle/11362/2593/1/S2011914_es.pdf.

7 En el ámbito del derecho internacional de la seguridad social y los instrumentos jurídicos expedidos por la Organización Internacional del Trabajo (OIT), se ha evidenciado con mayor rigor la inserción del concepto de seguridad social en la protección social, como se observa en la Recomendación núm. 202 de 2012 sobre los pisos de protección social, definidos en su numeral 2 como "conjuntos de garantías básicas de seguridad social definidos a nivel nacional que aseguran una protección destinada a prevenir o a aliviar la pobreza, la vulnerabilidad y la exclusión social".

8 Gómez-Arteaga, Natalie y Ocampo, José, "Los sistemas de protección social, la redistribución y el crecimiento en América Latina”, Revista de la CEPAL, núm. 122, 2017, pp. 1-27, disponible en: https:// repositorio.cepal.org/bitstream/ bandle/11362/42030/1/RVE122_Ocampo.pdf. 
protección social más integrales, por cuanto su cobertura en pensiones contributivas para personas mayores de 65 años es del 81.8\%, los asalariados afiliados a sistemas de pensiones corresponden al 77.1\%, y los asalariados afiliados a sistemas de salud están en el 90\%.

- El grupo de Venezuela, Colombia, Perú, México, Ecuador, República Dominicana y Panamá, en razón a que sus sistemas de protección social son intermedios, como quiera que su cobertura en pensiones contributivas para personas mayores de 65 años es del $28.4 \%$, sustancialmente baja en comparación con el primer grupo, los asalariados afiliados a sistemas de pensiones equivalen al 58.3\%, y los asalariados afiliados a sistemas de salud representa el $75.1 \%$.

- El grupo de El Salvador, Paraguay, Bolivia, Nicaragua, Guatemala y Honduras, en tanto que estos países disponen de sistemas de protección social limitados, siendo que su cobertura en pensiones contributivas para personas mayores de 65 años es apenas del 15.3\%, los asalariados afiliados a sistemas de pensiones corresponden escasamente al 37.6\%, y los asalariados afiliados a sistemas de salud equivalen al $41.9 \%$.

Desde una perspectiva histórica, el estudio señala que en ALC el enfoque más cercano al estado de bienestar sólo se concretó en Argentina, Costa Rica, Chile y Uruguay, sin llegar a desarrollarse como en los países industrializados. Sin embargo, en el caso de los países del Cono Sur, señala que su desarrollo económico les ha permitido aumentar la proporción del gasto social, en razón a que su gasto social en protección social como porcentaje del Producto Interno Bruto (PIB) es del 9.9\% y en salud del $5.1 \%$, versus el 3.7\% y $2.1 \%$ de los países intermedios y el $3.3 \%$ y $2.7 \%$ de los países limitados, respectivamente.

Asimismo, el estudio refiere que existe una asociación positiva entre un mayor PIB per cápita y un valor más alto del índice de protección social, pues cuanto más alto sea el PIB per cápita del respectivo país, mayor será su índice de protección social; de este modo, los países con sistemas de protección social limitados, como son El Salvador, Paraguay, Bolivia, Nicaragua, Guatemala y Honduras, son los que precisamente se ubican en el grupo de países con un PIB per cápita bajo; los países con sistemas de protección social intermedio, entre ellos, Venezuela, Colombia, Perú, Ecuador, República Dominicana, se encuentran en la zona media del PIB per cápita de la región, salvo Panamá, cuyo PIB per cápita es mayor pero registra un índice de protección social bajo, y México que a pesar de tener el segundo PIB per cápita más alto de ALC, dispone de un sistema de protección social intermedio. 
Algo análogo sucede con los países que disponen de sistemas de protección social integrales, es decir, Uruguay, Chile, Argentina y Brasil, que se ubican en el grupo de países ricos de la región, con excepciones puntuales como el caso de Costa Rica que, con un PIB ligeramente superior a la media regional, ha logrado la segunda puntuación más alta en el índice de protección social.

Estos estudios son coincidentes con las mediciones de las brechas de bienestar en ALC que clasifican a los Estados de acuerdo con su capacidad de generar ingresos a través del mercado laboral para sustentar a sus miembros, y a sus capacidades para proporcionar sustento y protección a quienes carecen de ingresos o acceden a ingresos insuficientes, que distribuyen a los países de la región en tres grandes grupos a partir de 2012, así:

- Países con brechas severas, entre los cuales se encuentran Bolivia, El Salvador, Honduras, Guatemala, Nicaragua y Paraguay;

- Países con brechas moderadas, comprendidos por Colombia, Ecuador, México, Perú y República Dominicana, y

- Países con brechas modestas, como son Argentina, Brasil, Costa Rica, Chile, Panamá, Uruguay y Venezuela?

Si bien en estas mediciones se advierte que no se cuenta con información de algunas variables socioeconómicas de los países del Caribe y las dificultades de analizar a Cuba por las diferencias de su sistema económico, a partir de la asociación de otras variables entre ellas su PIB y las tasas de dependencia, logran ubicar a Jamaica dentro del grupo de brechas moderadas, a Cuba y Trinidad y Tobago en la categoría de brechas modestas, y a Haití en el grupo de brechas extremas.

Todo lo anterior permite concluir entonces que, entre la aparente homogeneidad de la génesis y desarrollo de la seguridad social en la región, las asimetrías existentes entre los países pioneros, intermedios y tardíos en la implementación de la seguridad social, se han replicado directamente en el desempeño de sus sistemas de protección social, ámbito en el que la riqueza de los países también pareciera condicionar este desarrollo, salvo contadas excepciones.

\footnotetext{
9 Cecchini, Simone et al., "Sistemas de protección social en América Latina y el Caribe. Una perspectiva comparada", Serie Políticas Sociales, Santiago de Chile, CEPAL, núm. 202, 2014, pp. 1-50, disponible en: bttps:// wmw.cepal.org/es/publicaciones/36831-sistemas-proteccion-social-america-latina-caribe-perspectiva-comparada.
} 
Esta situación reviste tal gravedad, que el "Panorama Social de América Latina 2019" elaborado por la CEPAL, ${ }^{10}$ concluye que en 2018 el 30.1\% de la población regional estaba bajo la línea de pobreza, mientras que 10.7\% se encontraba bajo el umbral de la pobreza extrema, lo que significa que aproximadamente 185 millones de personas se encontraban en situación de pobreza, de las cuales 66 millones estaban en situación de pobreza extrema.

Entre tanto, en materia de pensiones, el estudio refiere que en 2017 sólo el $47.5 \%$ de la PEA de 15 o más años en el estrato de ingreso medio-bajos estaba afiliada o cotizaba a un sistema de pensiones, y que esta cobertura ascendía al $60.1 \%$ en los estratos medio-intermedios y a sólo el $69.8 \%$ en los estratos medio-altos, lo cual significa que casi una de cada tres personas económicamente activas no estaba afiliada ni cotizaba a un sistema de pensiones, mientras que la población de los estratos bajos y medios bajos contaba con una cobertura en el sistema de pensiones de aproximadamente $31.8 \%$.

\section{LA CONSAGRACIÓN CONSTITUCIONAL DEL DERECHO A LA SEGURIDAD SOCIAL EN AMÉRICA LATINA Y EL CARIBE}

工 a historia del constitucionalismo en ALC refleja que a partir de sus procesos independentistas ha atravesado por varias etapas, cada una de las cuales resolvió problemáticas particulares y ha dejado su impronta en la realidad constitucional de la región, al punto que en la fase del constitucionalismo social ubicada entre 1917 y 1980, e inaugurada con la expedición de la Constitución mexicana de 1917, se incorporaron los primeros derechos sociales en las cartas políticas de estos países, tal como se evidencia en las Constituciones de Perú en 1920, Chile en 1925, Ecuador en 1929, Uruguay y Brasil en 1934, Colombia y Venezuela en 1936, Bolivia en 1938, Nicaragua en 1939, Cuba y Paraguay en 1940, Panamá en 1941, República Dominicana en 1942, Costa Rica en 1943, Guatemala en 1945, Argentina en 1949, El Salvador y Haití en 1950, culminando en Honduras en 1957.

Aun así, las violaciones sistemáticas a los derechos humanos en varios de estos países durante las dictaduras y el retorno paulatino de la democracia desde la década de los ochenta, abrieron paso a una nueva etapa del constitucionalismo en ALC, expresado en las Constituciones de Colombia en 1991, Argentina en 1994, Venezuela en 1999, Ecuador en 2008, Bolivia en 2009,

10 Comisión Económica para América Latina y el Caribe, "Panorama Social de América Latina 2019", Santiago de Chile, 2019, disponible en: https:/ / repositorio.cepal.org/ bitstream/ handle/11362/44969/5/S1901133_es.pdf. 
México en 2011, entre otras, caracterizada por la ampliación de la lista de derechos sociales, el reconocimiento de comunidades que tradicionalmente habían sido marginadas del orden político, económico y social, la activación de la justicia constitucional, y la interpretación alternativa del derecho que le confiere valor normativo a la Constitución, para irradiar el ordenamiento jurídico con sus principios y valores permeando así a todas las ramas del derecho. ${ }^{11}$

Precisamente, se considera que un denominador común de la seguridad social en la región radica en su generalizada consagración constitucional, con cierto grado de homogeneidad y el fortalecimiento de los mecanismos de garantía constitucional para su exigibilidad; ${ }^{12}$ asimismo, se destaca que la constitucionalización de la seguridad social es un hecho incuestionable resultado del avance jurídico legislativo de la segunda mitad del siglo XX, dada su consagración en las diferentes Constituciones políticas iberoamericanas, y su reconocimiento como un derecho humano en la Declaración Universal de los Derechos Humanos de las Naciones Unidas. ${ }^{13}$

En retrospectiva, el proceso de incorporación constitucional del derecho a la seguridad social en las cartas políticas de los países de ALC, se presentó casi de manera sincrónica con la llegada del constitucionalismo social y los derechos laborales, contexto en el que es posible agruparlos de acuerdo con el año en que se insertó este derecho en sus respectivas Constituciones, de esta forma:

- Pioneros, como son Perú en 1920, ${ }^{14}$ Chile en 1925, ${ }^{15}$ Ecuador en 192916 y México con la reforma constitucional del mismo año; ${ }^{17}$

11 Uprimny, Rodrigo, "Las transformaciones constitucionales recientes en América Latina: tendencias y desafíos", 2011, disponible en: http://wmw.pensamientopenal.com.ar/system/files/2011/04/doctrina28469.pdf.

12 Panizo, José, "La seguridad social en las Constituciones iberoamericanas", OISS-AECID, 2017, disponible en: http://mmw.oiss.org/IMG/pdf/La_Seguridad_Social_en_las_Constituciones_Iberoamericanas.pdf.

13 Ruiz, Ángel, "La constitucionalización del derecho humano a la seguridad social en Latinoamérica", Revista Latinoamericana de Derecho Social, UNAM, núm. 19, 2014, pp. 63-86, disponible en: http:/ / wmw.scielo.org. $m x$ / scielo.php?script=sci_arttextEopid $=S 1870-46702014000200063$.

14 Artículos 47, 55 y 56.

15 Artículo 10, numeral 14.

16 Artículo 151.

17 En la reforma constitucional del 6 de septiembre de 1929, se modificó el artículo 123 de la Constitución de 1917 para insertar directamente la seguridad social al modificar su numeral 
- Intermedios, entre los que se encuentran Brasil ${ }^{18}$ y Uruguay en 1934, ${ }^{19}$ Venezuela en 1936, ${ }^{20}$ Bolivia en 1938, ${ }^{21}$ Nicaragua en 1939, ${ }^{22} \mathrm{Cuba}^{23}$ y Paraguay en 1940, ${ }^{24}$ República Dominicana en $1942,{ }^{25}$ Costa Rica en $1943,{ }^{26}$ El Salvador ${ }^{27}$ y Guatemala en $1945,{ }^{28}$ Panamá en $1946{ }^{29}$ y Argentina en $1949,{ }^{30} \mathrm{y}$

- Tardíos, conformado por Haití en 1950, ${ }^{31}$ Honduras en 195732 y Colombia en 1991.33

GRÁFICA 1. El constitucionalismo social en ALC y la primera mención constitucional del derecho a la seguridad social

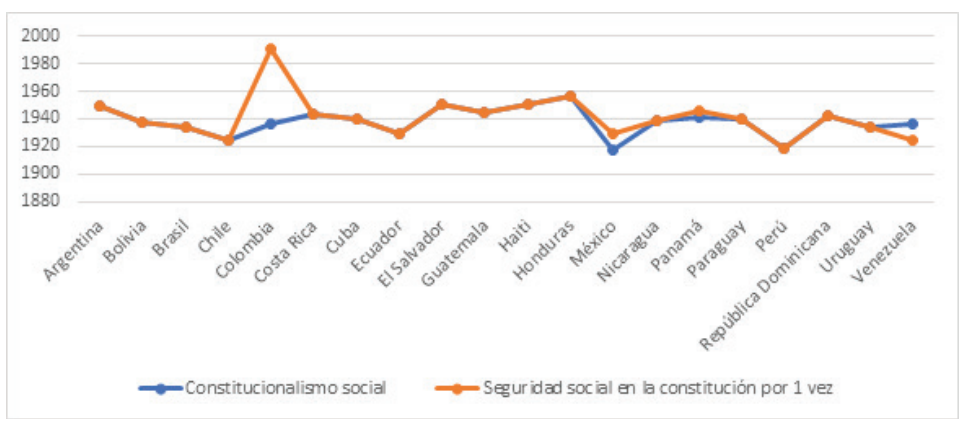

FUENTE: Elaboración propia

XXIX, declarando "de utilidad pública la expedición de la Ley del Seguro Social y ella comprenderá seguros de la invalidez, de vida, de cesación involuntaria del trabajo, de enfermedades y accidentes y otras con fines similares".

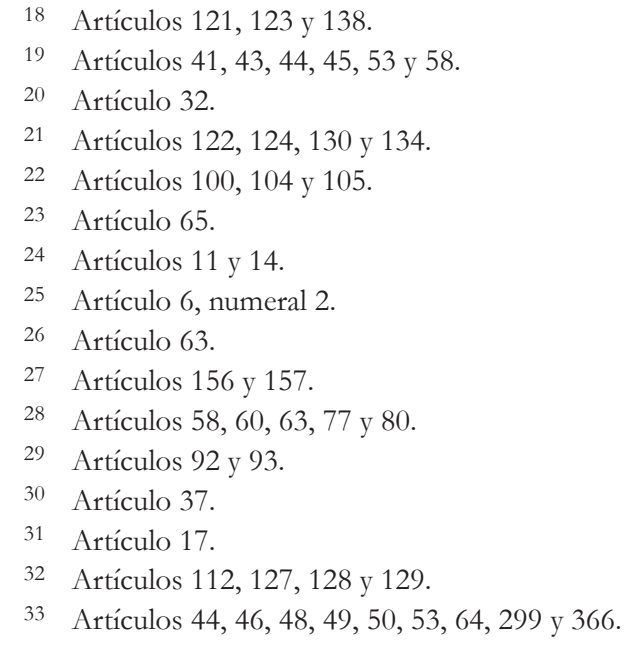


Empero, mucho antes del arribo del constitucionalismo social y la inserción constitucional del derecho a la seguridad social, en la mayoría de países de la región se evidenciaron esfuerzos incipientes por concretar este derecho durante el siglo XIX y principios del siglo XX, enfocados esencialmente en la asistencia social, la garantía de una pensión que se extendió gradualmente hacia determinados sectores de trabajadores, normas protectoras de los trabajadores que obligaban a sus patronos al pago de una indemnización en caso de accidente de trabajo, hasta la expedición de las primeras leyes de seguro social obligatorio desde la década de los veinte hasta los ochenta del siglo pasado. ${ }^{34}$

Así, todos los países latinoamericanos y del Caribe latino consagran el derecho a la seguridad social en sus textos constitucionales vigentes, y en algunos casos los componentes orgánicos, presupuestales, financieros y funcionales de las entidades encargadas de la materialización de este derecho, ${ }^{35}$ de este modo: ${ }^{36}$

- Argentina: Constitución Política de 1853 y sus reformas. Artículos 14 bis, 42, 75 numeral 12, y 125.

- Bolivia: Constitución Política de 2009 y sus reformas. Preámbulo, artículos 8, 9, 18, 19, 30 (numeral 13), 35 al 48; 50, 60, 67 al 72; 105, 298, 299, 304, 306, 321 у 341.

- Brasil: Constitución Política de 1988 y sus reformas. Artículos 3o., 6o., 7o., 22 (numeral XXIII), 109 (numeral 3), 149 (numeral 1), 165 (numeral 5), 167 (numeral VIII), 179 y 193 al 204.

- Chile: Constitución Política de 1980 y sus reformas. Artículos 19 (numerales 9 y 18), 63 (numeral 4) y 65.

- Colombia: Constitución Política de 1991 y sus reformas. Artículos 44, 46, 48, 49, 50, 53, 64, 299 у 366.

- Costa Rica: Constitución Política de 1949 y sus reformas. Artículos 63, 65, 72, 73, 74 y 177.

34 Monsalve, Martha et al., Historia de la seguridad social en América Latina, Instituto Latinoamericano de Derecho del Trabajo y de la Seguridad Social, Universidad de Medellín. 2017.

35 El Convenio 102 de 1952 refiere que la seguridad social consta de nueve áreas, como son: i) asistencia médica; ii) prestaciones monetarias de enfermedad; iii) prestaciones de desempleo; iv) prestaciones de vejez; v) prestaciones en caso de accidentes del trabajo y enfermedad profesional; vi) prestaciones familiares; vii) prestaciones de maternidad; viii) prestaciones de invalidez; y ix) prestaciones de sobrevivientes.

36 A pesar de la evolución reciente del concepto de seguridad social hacia la protección social, en ninguna de las Constituciones de ALC se consagra un derecho autónomo a la protección social. 
- Cuba: Constitución Política de 2019. Artículos 46, 68, 69, 70, 71, 72, 90 (literal i), 191 (literal i), 199 y 201.

- Ecuador: Constitución Política de 2008 y sus reformas. Artículos 30. (numerales 1 y 5), 14, 32, 33, 34, 36, 37, 38, 43, 45, 47, 49, 50, 66 (numeral 2), 83 (numeral 15), 261 (numeral 6), 292, 326 (numeral 15), 333, 340 y 358 al 376.

- El Salvador: Constitución Política de 1983 y sus reformas. Artículos 1o., 35, 37, 40, 43, 44, 45, 50 y 65 al 70.

- Guatemala: Constitución Política de 1985 y sus reformas. Artículos 47, 51, 52, 53, 66, 67, 68, 69, 93 al 102; 105, 106, 115 y 117.

- Haití: Constitución Política de 1987 y sus reformas. Artículos 19, 22, 23 y 35 .

- Honduras: Constitución Política de 1982 y sus reformas. Artículos 111, 117, 119, 120, 123, 124, 126, 127, 141 al 150 y 245 (numeral 29)

- México: Constitución Política de 1917 y sus reformas. Artículos 1o., 2o., 4o., 18 y 123.

- Nicaragua: Constitución Política de 1987 y sus reformas. Artículos 39, 59, 61, 62, 63, 64, 74, 76, 77, 82 у 105.

- Panamá: Constitución Política de 1972 y sus reformas. Artículos 26, 37, 40, 56, 72, 109, 110, 111, 113, 114, 115, 116, 117, 316 у 320.

- Paraguay: Constitución Política de 1992 y sus reformas. Artículos 49, 54, 55, 57, 58, 61, 68 al 72; 89, 95, 99, 103 y 130.

- Perú: Constitución Política de 1993 y sus reformas. Artículos 4o., 6o., 7o., 8o., 9o., 10, 11, 12, 58 у 59.

- República Dominicana: Constitución Política de 2015 y sus reformas. Artículos 7o., 8o., 55 al 62 y 65.

- Uruguay: Constitución Política de 1967 y sus reformas. Artículos 38, 42, 44, 45, 46 y 195.

- Venezuela: Constitución Política de 1999 y sus reformas. Artículos 75, 76, 78, 80, 83 al 88, 100, 111, 122, 144, 156 (numerales 22, 23, 24 y 32), $178,184,311$ y 328.

Ahora bien, analizando esta información en términos cuantitativos es posible graficarla de la siguiente forma: 
Esta revista forma parte del acervo de la Biblioteca Jurídica Virtual del Instituto de Investigaciones Jurídicas de la UNAM http://www.juridicas.unam.mx

GrÁFICA 2. Número de artículos en la Constitución vigente de cada país relacionados con el derecho a la seguridad social.

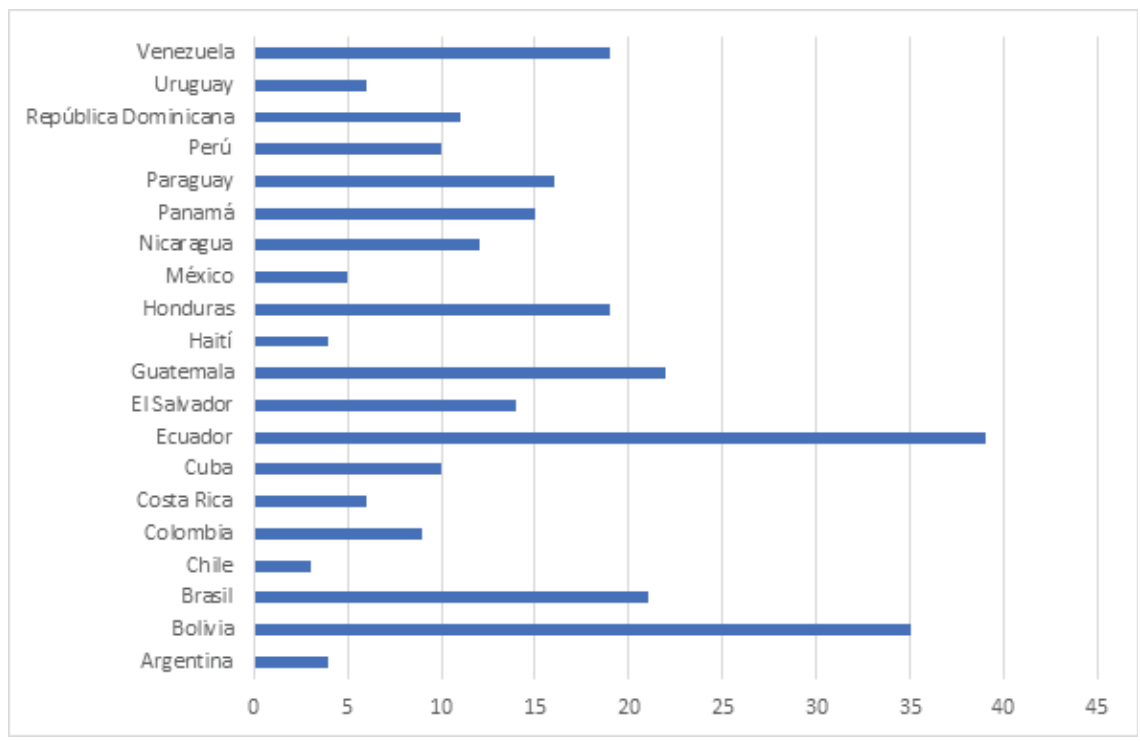

FUENTE: Elaboración propia.

Nótese que en la región existen variaciones sustantivas en cuanto al número de artículos que aluden al derecho a la seguridad social o alguno de sus componentes, pues en los países con sistemas de protección social integrales, como Argentina, Chile, Costa Rica y Uruguay, la incorporación constitucional del derecho a la seguridad social es restringida, lo que demuestra que la garantía del derecho a la seguridad social y en general de los DESC también tiene connotaciones políticas y económicas, en la medida que las capacidades económicas de los Estados y la voluntad política de los gobiernos, desempeñan un papel primordial que no se puede perder de vista al momento de analizar su cumplimiento.

En contraposición con lo anterior, Ecuador y Venezuela, que se caracterizan por disponer de sistemas de protección social intermedios, así como Bolivia, Guatemala, Honduras y Paraguay, cuyos sistemas de protección social son limitados, construyeron los articulados constitucionales de la seguridad social más robustos de toda la región, en los que inclusive se insertaron as- 
pectos orgánicos, presupuestales, financieros y funcionales que podrían ser regulados por leyes o normas de inferior jerarquía.

Sin embargo, este análisis se relativiza en el caso de Brasil, en la medida que abarcó una de las regulaciones constitucionales de la seguridad social más extensas de ALC, pero a su vez logró estructurar un sistema de protección social integral y con amplias capacidades para la generación de bienestar, ocurriendo lo contrario con Haití, cuya consagración constitucional del derecho a la seguridad social es discreta, pero su brecha de bienestar social sigue siendo extrema.

\section{CONCLUSIONES}

\section{T}

a dilatada trayectoria histórica del derecho a la seguridad social y su Imasiva constitucionalización en ALC, contrasta con la situación persistente de pobreza, desigualdad y baja cobertura de los sistemas contributivos de la seguridad social en la PEA de la región, ámbito en el que la génesis y el desarrollo de estos sistemas, así como los niveles de generación de riqueza de los países de la región, tienen una incidencia directa en el actual desempeño de sus sistemas de protección social y la capacidad de creación de bienestar para todos sus habitantes.

Del mismo modo, es posible concluir que en ALC, a mayor realización del derecho a la seguridad social, menor es el interés de consagrarlo constitucionalmente, mientras que a menor goce efectivo del mismo, mayor es el reconocimiento constitucional que recibe, en comparación con los países desarrollados en donde los derechos sociales se encuentran garantizados a nivel legislativo y no requieren consagración constitucional. ${ }^{37}$

Tal situación podría obedecer a que el derecho a la seguridad social ha sido una reclamación histórica y permanente de la ciudadanía, por lo que de alguna manera su prolija y exhaustiva consagración constitucional, es decir como norma del más alto rango normativo, se asume como prenda de garantía para exigir a los Estados su cumplimiento, ahora bajo la lógica de la constitucionalización del derecho y los nuevos constitucionalismos latinoamericanos.

Empero, la actualidad política de la región permite advertir que existe una línea muy estrecha entre la proclamación de los derechos sociales y el populis-

37 Arango, Rodolfo, "Constitucionalismo social latinoamericano", 2010, p. 4, disponible en: bttps:/ / archivos.juridicas.unam.mx/ www/bjv/libros/6/2894/6.pdf. 
mo, toda vez que este último ha sido parte de la estrategia de algunos gobiernos de ALC para perpetuarse en el poder, indistintamente del perfil político en que se ubican, a través de la proclamación extendida de derechos sociales consagrados en reformas constitucionales que usualmente promueven y que son útiles a sus fines políticos, sin dimensionar las verdaderas capacidades administrativas, económicas y fiscales del respectivo país para garantizarlos, pasando de este modo del populismo político al populismo normativo.

De manera que este fenómeno de consagración constitucional inusitada del derecho a la seguridad social en ALC, podría ser una expresión del populismo normativo imperante en varios países de la región, donde paradójicamente la falta de efectividad de sus sistemas de protección social y los altos niveles de pobreza y desigualdad social, han sido el caldo de cultivo para que esta práctica política y jurídica se integre a un círculo vicioso que ralentiza el progreso de los pueblos.

En este punto, es errado asumir que el constitucionalismo por sí solo puede actuar como agente de cambio para mejorar los índices de protección social en ALC, pues en esta tarea confluyen otras variables de índole económico, político y social, según se ha reflejado en países que actualmente gozan de sistemas de protección social integrales, en los que el discurso constitucional del derecho a la seguridad social no parece ser un asunto determinante para su efectividad.

Por el contrario, es menester reivindicar el papel crucial de la capacidad de acción comunicativa en las sociedades para procurar la búsqueda de la integración social y la conciliación de todos los intereses involucrados en la consagración y materialización de los derechos constitucionales, pues la carencia de este ejercicio desencadena frustraciones ciudadanas e incredulidad en la democracia al abarcar derechos que en la práctica son imposibles de cumplir.

Para estos fines, si bien es cierto que cada Estado es soberano para definir la forma en que garantiza el derecho a la seguridad social a sus ciudadanos, también es importante que trascienda del discurso constitucional de la seguridad social, hacia la acción y la puesta en marcha de verdaderas políticas públicas que aterricen este derecho en sus diversos enfoques y en aspectos concretos que progresivamente conlleven hacia su cumplimiento, identificando necesidades de asistencia técnica, cooperación internacional, nuevas fuentes de financiación, formas de integración regional o subregional, entre otros, todo ello en función del logro de los objetivos de desarrollo sostenible relacionados con la protección social. 


\section{FUENTES DE INVESTIGACIÓN}

ARANGo, Rodolfo, Constitucionalismo social latinoamericano, 2010, disponible en: https: / / archivos.juridicas.unam.mx/ wmw/ bjv/ libros/6/2894/6.pdf.

CECCHINI, Simone y MARTínez, Rodrigo, "Protección social inclusiva en América Latina. Una mirada integral, un enfoque de derechos", Santiago de Chile, 2011, disponible en: https:/ / repositorio.cepal.org/ bitstream/ handle/11362/2593/1/S2011914_es.pdf.

CECCHINI, Simone et al., "Sistemas de protección social en América Latina y el Caribe. Una perspectiva comparada", Serie Políticas Sociales, Santiago de Chile, CEPAL, núm. 202, disponible en: https://www.cepal.org/es/ publicaciones/36831-sistemas-proteccion-social-america-latina-caribe-perspectiva-comparada.

COMISIÓN ECONÓMICA PARA AMÉRICA LATINA Y EL CARIBE, "Panorama Social de América Latina 2019", Santiago de Chile, 2019, disponible en: https:/ / repositorio.cepal.org/ bitstream/ handle/11362/44969/5/S1901133_ es.pdf

DuRANGO, Gerardo, "El principio discursivo y los derechos fundamentales en la teoría habermasiana", Revista Opinión Jurídica, Universidad de Medellín, 2006.

GÓMEZ-ARTEAGA, Natalie y OCAMPO, José, "Los sistemas de protección social, la redistribución y el crecimiento en América Latina", Revista de la CEPAL, núm. 122, 2017, disponible en: https://repositorio.cepal.org/bitstream/ handle/11362/42030/1/RVE122_Ocampo.pdf.

Mesa-Lago, Carmelo, "Las reformas de pensiones en América Latina y su impacto en los principios de la seguridad social", Serie 144 - Financiamiento del desarrollo, 2004, disponible en https:// wnw.cepal.org/es/publicaciones/5126reformas-pensiones-america-latina-su-impacto-principios-la-seguridad-social.

Monsalve, Martha et al., Historia de la seguridad social en América Latina, Instituto Latinoamericano de Derecho del Trabajo y de la Seguridad Social, Universidad de Medellín, 2017.

NUGENT, Ricardo, "La seguridad social: su historia y sus fuentes", en BUEN Lozano, Néstor de, y Morgado Valenzuela, Emilio (coords.), Instituciones de derecho del trabajo y de la seguridad social, México, AIDTSS-UNAM, 1997, disponible en: bttps:// biblio.juridicas.unam.mx/bjv/detalle-libro/139-instituciones-de-derecho-del-trabajo-y-de-la-seguridad-social. 
PANIZO, José, "La seguridad social en las Constituciones iberoamericanas", OISS-AECID, 2017, disponible en: http:// www.oiss.org/IMG/pdf/La_Seguridad_Social_en_las_Constituciones_Iberoamericanas.pdf.

RuIZ, Ángel, "La constitucionalización del derecho humano a la seguridad social en Latinoamérica", Revista Latinoamericana de Derecho Social, UNAM, núm. 19, 2014, disponible en: http:/ / wmw.scielo.org.mx/scielo.php?script=sci_ar ttexteopid $=$ S1870-46702014000200063.

UPRIMNY, Rodrigo, "Las transformaciones constitucionales recientes en América Latina: tendencias y desafíos", 2011, disponible en: http:// wmw. pensamientopenal.com.ar/system/files/2011/04/doctrina28469.pdf. 